I have breathed the ether on several occasions, and think its effects may be divided into three stages or degrees. The first is merely a pleasurable feeling of half intoxication; the second is one of extreme pleasure, being similar to the sensations produced by breathing nitrous oxide, or laughing gas; there exists in this stage a perfect consciousness of everything said or done, but generally an incapability of motion; in this stage, also, there is not exactly an insensibility to pain, but rather an indifference, " a care-for-nothing sort of feeling;" and if surgical opcrations are done in this stage, the patients almost always recover before the operations are completed, and the results are unsatisfactory. There can be no doubt that most of the failures may be attributed to this cause, as occurred to-day in a boy operated upon by $\mathbf{M r}$. Ferguson, at King's College Hospital.

The third stage, the only one, $\dot{I}$ think, for performing operations in, is one of profound intoxication and insensibility. The individual is completely lost to pain, and to external impressions; the muscles become prostrate, the circulation lessens, and the temperature falls; but the mind is often revelling in the most pleasurable regions, as in a dream; this, no doubt, depending much upon the temperament of the individual, and probably, also, on the pliysical effects of the operation on the nerves, as very often there is a considerable moaning, and an attempt to move, when under the influence of the knife.

There appears to be some difference of opinion as to the action of ether upon the system; but there can be but little doubt, that when taken into the lungs, its elements rapidly unite with the oxygen of the arterial blood, rendering it venous, and that it stops the metamorphosis of the tissues, producing a diminution of the temperature of the body, and also a diminution of vital energy, in the same way as the vapour of alcohol, only with greater rapidity.

I remain, Sir, your obedient and humble servant, Framcis Plomeex, M.D., F.L.S., \& c.

\section{ETHERIZATION IN TETANUS.}

To the Editor of The Lancex.

Sir,-I see, by your leader of the 16th inst., that in your remarks upon the utility of etherization you state that "some have thought of its extension to medicine, and tetanus and hydrophobia have been mentioned as likely to be benefited by its use. Any such trials will assuredly end in disappointment; these diseases being diseases of motion, not of sensation," \&c. You will perhaps be pleased to learn that this opinion is strictly borne out by fact, as far as the results of a single example can be relied upon. Having recently liad a very severe case of tetanus under my care, I thought that I would give the ether a trial; I found, however, what a little reflection might have taught me, that it was even worse than useless, and that the spasms were fearfully augmented by every attempt at inhalation. As the action of ether is strictly, as far as I have been able to judge, confined to the cerebral portion of the nervous system, and as the excito-motory system is known to manifest an increase of action in proportion as volition is obliterated, (witness paraplegia, decapitation, \&c.,) it might be predicted that diseases in which the true spinal marrow is mainly implicated would not only not be reached by the ether, but would be aggravated by it. Excuse this hasty note, and believe me, dear Sir, yours obediently,

Bury St. Edmund's, Jan. 1846.

W. H. Ranking, M.D.

\section{Correspondente.}

\section{REPLY TO DR. MARSHALL HALL. To the Editor of The LaNCeT.}

Sir, - In last Saturday's Lancet appears a letter from Dr. M. Hall, in which he endeavours to vindicate himself from the charge, brought against him in the last number of the Medico-Chirurgical Review, of unjustifiable cruelty in the performance of experiments upon living animals. One would suppose, from the tone of that letter, and of the accompanying extract from his work, "On the Circulation of the Blood," that the experiment which called forth our censures had been instituted upon an animal that was deprived of sensation. That such was not the case on the occasion referred to is abundantly obvious from the very terms in which Dr. Hall's coadjutor has described the experiment in question.

"In a spaniel dog, a portion of the skull was removed by the trephine; but from the thickness of the temporal muscle, and the effusion of blood, it was very difficult to accomplish; the instrument therefore penetrated through the dura mater into the brain. The immediate effect was paralysis of the opposite side of the body; the animal, when placed on the ground, falling on that side, and being unable to rise. It nanaged, however, to struggle to the wall and comer, when, on being raised, it supported itself by leaning the paralyzed side against it. On introducing the finger, and pressing on the brain anteriorly, the eyelids closed, and the animal appeared as if asleep, breathing heavily." ...... "The cerebrum was next completely broken up and removed, and the top of the skull talyen off, The pupil of the eye became very much dilated, and the animal lost all sensation."

Can it be conceived that the infliction of such horrible suffering (for the animal, it would seem, was quite sensible at the commencement of the experiment) is necessary for the elucidation of any important truth, or for the advancement of that science on which, according to Dr. Hall, "not only the preservation, but the restoration, of strength and liealth depend." We cannot believe that even he will give the sanction of his authority to the repetition of so revolting an exhibition.

To base the justifiableness of vivisections on the permission or injunction to "liill and eat," is, to say the least of it, a strange misapplication of scriptural language. He who gave that permission, hath also told us-and how startling is the announcement - that "not even a sparrow falleth to the ground without His knowledge."

It would be easy to show how utterly opposed to the very principles which Dr. Hall has himself laid down in the extract quoted from his work on the Circulation, was the experiment upon which we have commented, not to mention some other experiments described or hinted at in the recently-published volume of the "Practical Observations and Suggestions;" but this is unnecessary at present.

The Reviewer of Dr. Hall's ObserVATIONS \&C. IN THE LAST No. OF the "Med.-Chir. Review."

$*_{*}^{*}$ The questions to be decided are-1. Are experiments on living animals, or vivisections, as they have been nicknamed, justifiable? Wesuppose there can be no doubt of the affirmative, or else the whole science of physiology falls to the ground. 2. Granting the first position, did Dr. Marshall Hall ever devise and perform an operation without such an end in view as to justify its performance? We believe not. We have ourselves seen Dr. Hall perform a great number of his experiments, and we have ever seen him follow the humane principles laid down by himself in the introduction to the Physiology of the Circulation.-ED. L.

\section{MIDWIFERY FEES.}

To the Editor of THE Lancet.

SiR,-Being an honest follower of Esculapius, I am profoundly ignorant of "Secondaries' Court," and hope to remain equally unacquainted with Mr. Secondary James, who estimates very lightly the services of a medical man.

This learned gentleman is made to state, in the Morning Chronicle of the $F$ th instant:- "Two guineas now-a-days appeared a handsome price for an accouchement. He thought few ladies who kept their carriages would give more than $5 l .5 s . "$ What will Dr. Locock say to this new and legal adjudication of fees? I should like to know, Mr. Editor, what justice there is in Mr. Secondary James fixing in so summary a manner the sum of $2 l .2 s$. No fact more than this judicial interference with our fees proves the necessity for an effective system of registration; for upon that will follow a fair system of undisputed remuneration.Yours truly,

London, Jan. 1847. Adyerso J A COBO.

\section{COURTS-MEDICAL.-WIGAN $v$. GREGORY. [LetTer from Mr. W. Robins.] To the Editor of The Lanofit.}

SIR, - I cannot help thinking the majority of your readers will be ready to admit that the cause of Wigan versus Gregory should be considered in some other light than as a mere personal dispute; and that some more lasting effect ought to be produced by it than by an ordinary nine days' wonder. In my humble opinion, there are, in this case, circumstances which must produce, sooner or later, such an impression on the pro- 